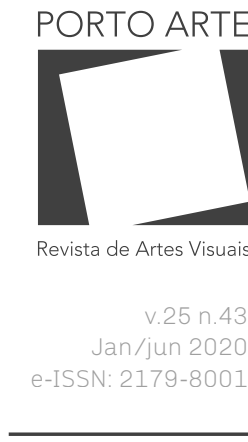

Notas sobre a História das Exposições no discurso curatorial Notes on Exhibition History in Curatorial Discourse*

\title{
Felix Vogel
}

ORCID: 0000-0002-6393-5386

University of Basel

\section{Resumo}

O artigo discute como a crescente importância e a transformação das exposições desde os anos 1960 têm motivado um envolvimento mais profundo com sua própria história. Nesse sentido, o autor assinala a importância dos programas de estudos curatoriais estabelecidos desde os anos 1980, uma vez que são ambientes de treinamento prático e pesquisa histórico-teórica. Contudo, argumenta que os discursos sobre as exposições ainda são quase que exclusivamente enunciados pelos próprios curadores, que a partir de seu lugar de fala se colocam ao mesmo tempo como sujeito e objeto. Assim, ao figurarem como protagonistas da História das Exposições, os curadores acabam por criar novos cânones, resultando em possível padronização e homogeneização dos modelos expositivos.

\section{Palavras-chave}

Discurso curatorial. História das Exposições. Estudos curatoriais. Lugar de fala. Cânones expositivos.

*Publicado originalmente em: On Curating - (New) Institution(alism), n. 21 Zurique, dez. 2013, p. 4654. Este texto é uma versão ligeiramente reformulada de um artigo de 2013 no âmbito do 2.Schweizerischer Kongress für Kunstgeschichte (Segundo Congresso Suiço de História da Arte) em Lausanne, na seção Handling Exhibitions Konvergenzen zwischen Praxis und Theorie (Manuseando Exposições - Convergências entre prática e teoria).

\section{Abstract}

This article discusses how the growing importance and transformation of exhibitions since the 1960s have motivated a deeper involvement with their own history. In this sense, the author points out the relevance of curatorial study programs established since the 1980s, once they are environments for practical training and historical-theoretical research. However, he argues that discourses about exhibitions are still almost exclusively enunciated by curators themselves, who, from their speaker position, place themselves at the same time as subject and object. Thus, by appearing as protagonists in the History of Exhibitions, curators end up creating new canons, resulting in possible standardization and homogenization of exhibition models.

Keywords

Curatorial discourse. Exhibition histories. Curatorial studies. Speaker position. Exhibition canon. 


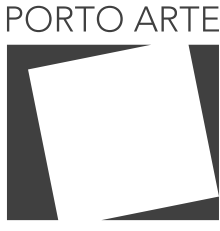

Revista de Artes Visuais

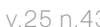

Jan/jun 2020

Em 1999, o Clark Institute organizou uma conferência muito discutida, intitulada The Two Art Histories: The Museum and the University ${ }^{1}$, cujo tema foi a suposta lacuna entre a História da Arte nos contextos dos museus e das universidades. Os organizadores pretendiam examinar o preconceito de que a História da Arte acadêmica se interessa demais pela teoria e negligencia o objeto; enquanto o museu está ocupado principalmente com questões de financiamento e público visitante, criando baixas expectativas quanto a sua pesquisa. Se desde então essa situação melhorou ou se intensificou, não é uma pergunta que eu seja capaz de responder. Em vez disso, gostaria de tratar de um problema relacionado que não diz respeito à História da Arte como um todo, mas que, após a conferência do Clark Institute, podemos nos referir como The Two Exhibition Histories. 0 que me interessa aqui é principalmente o discurso em torno das exposições que se estabeleceu para além da universidade, mas também em grande parte fora do museu, e que provisoriamente intitularei como o "discurso curatorial da História das Exposições".2

É impressionante que o tema das exposições - e também de sua história - tenha apenas sido adequadamente estabelecido como objeto de pesquisa nos últimos 20 anos; e particularmente na última década, tanto na História da Arte como em campos relacionados. Publicações, conferências, projetos de pesquisa, cursos universitários e periódicos atestam isso. Desde 2011, a Central Saint Martins College, em Londres, oferece até um curso de pós-graduação em Exhibition Studies. A cada ano acadêmico, seis ou sete alunos estudam no programa, sendo apenas uma fração com experiência em História da Arte, e boa parte nos campos de Belas Artes, Design ou Estudos Curatoriais.

Esse amplo interesse pela História das Exposições em parte se deve certamente, como afirma Bruce Altshuler (2010/2012, p. 5), ao interesse pela chamada "nova" história da arte por abordagens do contexto-específico e sócio-históricas, embora isto indique uma atraso tardio notável. Inquestionavelmente, a crescente visibilidade e transformação das exposições desde os anos 1960 motivou um envolvimento mais profundo com sua história. Por um lado, isso se refere à criação de novas bienais e instituições para a exibição de arte contemporânea e à expansão do mercado de arte com suas inúmeras exposições em galerias e feiras de arte, bem como à crescente temporalização do museu: além de reformas e ampliações construídas para aumentar o espaço para exposições temporárias - principalmente devido a fatores econômicos e de marketing -, um envolvimento crítico ou artístico com a coleção tornou-se quase uma necessidade para qualquer museu. Embora essas abordagens sejam sempre baseadas na coleção permanente, as formas de apresentação se assemelham cada vez mais às das exposições temporárias, substituindo modelos de exibição de coleções

\footnotetext{
1- Os anais da conferência foram publicados como: HAXTHAUSEN, Charles W. (ed.). The two art histories The museum and the university. Yale: Yale University Press, 2002

2- Falar de apenas "duas" Histórias das Exposições é duplamente presunçoso. Em primeiro lugar, nunca há uma história, histórias são sempre plurais e os dois campos mencionados - História da Arte acadêmica e Estudos Curatoriais - são heterogêneos internamente, e freqüentemente se sobrepõem entre si e em campos adjacentes. Ainda assim, eu argumentaria que certas tendências disciplinares podem ser agrupadas Em segundo lugar, uma História das Exposições dividida em apenas duas esferas também é deficiente. Podemos considerar o envolvimento dos artistas com exposições históricas e formatos de exibição (começando com artistas da chamada crítica institucional até posicionamentos contemporâneos como os de Martin Beck, Walter Benjamin ou Joseph Dabernig), assim como reconstruções de exposições (por exemplo, "When Attitudes Become Form", em Berna, na Suíça, em 1969, e sua versão em Veneza, em 2013, na Fondazione Prada), como formas artísticas ou "materiais" da História das Exposições.
} 


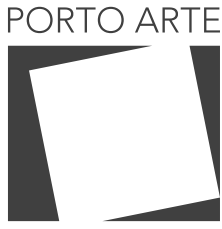

Revista de Artes Visuais

$\vee 25 n .43$

Jan/jun 2020 e-ISSN: 2179-8001

supostamente rígidos, autoritários e atemporais. Por outro lado, a exposição está se transformando na medida em que devemos considerar todo um novo repertório de tipologias que dissolvem os formatos tradicionais de mostras solo, coletivas e temáticas. Podemos mencionar exposições da categoria "estética relacional", que, de acordo com Nicolas Bourriaud (2002, p. 18), tornou-se uma "arena de troca"; e também o tipo de exposições baseadas em projetos - ou pesquisas - que giram principalmente em torno da produção de discurso. Nesse contexto, devemos considerar o desenvolvimento de práticas artísticas como a arte conceitual ou a crítica institucional, ou seja, o deslocamento da obra de arte (autônoma) para questões de contexto e condições de produção, com maior foco na própria exposição. Peter Osborne (2013, p. 167) menciona que é a "forma de exibição" que "preenche o requisito de fornecer significado", ou seja, a exposição como uma "unidade de significado artístico e objeto de intenção construtiva". Além disso, e a meu ver o mais importante, é o estabelecimento de programas de Estudos Curatoriais - uma vez que são concebidos como ambientes de treinamento prático e de pesquisa teórica. Os programas de Estudos Curatoriais oferecidos esporadicamente desde o final da década de 1980 e o início dos 1990, mas com maior intensidade desde o início da década de 2000, surgiram não apenas nos fundamentos de uma nova e ampliada função da exposição; mas também a refletiram, no sentido de que exigiram um conhecimento de seu objeto de estudo para, em primeiro lugar, construí-lo. ${ }^{3} \mathrm{Em}$ outras palavras: a profissionalização e a formalização subsequente do campo curatorial pressupunham um sentido de sua própria história (SHEIKH, 2010/2012, p. 15). Não é de surpreender, portanto, que não seja a própria História da Arte que tenha contribuído com a maior parte das publicações sobre História das Exposições na última década que, ao contrário, emergiram nos arredores dos Estudos Curatoriais. ${ }^{4}$

Se no que se segue irei me limitar quase que exclusivamente à História das Exposições no discurso curatorial, isto não se destina somente a criar uma distinção de julgamento entre este discurso, por um lado, e o da História da Arte acadêmica, por outro. Pelo contrário, é uma delimitação necessária para fortalecer e focalizar meu argumento. Tal foco pode tornar mais visíveis as estratégias territoriais, o que significa fazer perguntas precisas como: quem define conceitos e terminologias? Quem determina o cânone e, portanto, a História das Exposições? E de que maneira? Suspeito também que um exame exaustivo desse discurso sobre as exposições forneça algumas pistas para a questão da homogeneização dos formatos expositivos, o que também nos permite tirar algumas conclusões retrospectivas sobre o suposto formato transnacional das exposições internacionais de larga escala desde o final dos anos 1980.

\footnotetext{
3- Uma análise das intenções, dos objetos, dos métodos (de ensino), das implicações políticas e da maneira como o conhecimento é produzido nesses programas e por meio deles seria um estudo à parte que valeria a pena

4- Isso não quer dizer que não haja excelentes publicações e projetos de pesquisa ambiciosos sobre essas questões na História da Arte acadêmica. Podemos mencionar os seguintes exemplos: Mary Anne Staniszewski, com The Power of Display. A History of Exhibition Installations at the Museum of Modern Art (Cambridge, Mass.: MIT Press, 1998); Bruce Altshuler, com The Avant-Garde in Exhibition: New Art in the 20th Century (New York: Abrams, 1994) e com Exhibitions That Made Art History, Vol. 1: Salon to Biennial 18631959, Vol. 2: Biennials and beyond 1962-2022 (London: Phaidon, 2008 e 2013). Também a série Exhibition Histories, publicada pela editora inglesa Afterall, sobre exposições como "When Attitudes Become Form", "Magiciens de la Terre" e as numerosas exposições de Lucy Lippard. Outro exemplo de estudo extenso é o dirigido por Beat Wyss, na Bienal de Veneza, pelo Instituto Suíço de Pesquisa de Arte de Zurique.
} 


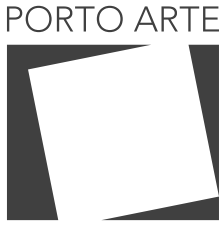

Revista de Artes Visuais

$\vee 25 n .43$

Jan/jun 2020 e-ISSN: 2179-8001

Onde, então, esse discurso da História das Exposições se manifesta? De que publicações e de que maneira a História das Exposições tem sido praticada no discurso curatorial? Nos últimos anos, por exemplo, foi publicada uma série de estudos aprofundados sobre Harald Szeemann (MÜLLER, 2006; AUBART, DERIEUX, 2007; BEZZOLA, KURZMEYER, 2007). Tais publicações, em parte material de arquivo, em parte biográfico - às vezes parecidos com a hagiografia -, de um único curador; agora têm aparecido não apenas para o über-curador Szeemann, mas também para outras figuras similares. Uma grande parte do discurso é moldada por coleções de entrevistas, como as 11 entrevistas de Hans-Ulrich Obrist com importantes curadores5 publicadas em 2008 como "A Brief History of Curating" (2011), que está agora em sua quinta edição e é o único best-seller da editora JRP Ringier. Em seu prefácio e posfácio, bem como nas entrevistas individuais, essa publicação se apresenta como uma contribuição decisiva para a História das Exposições. Outro exemplo é a revista "The Exhibitionist", lançada semestralmente desde 2010. A revista afirma ser a primeira6 explicitamente dedicada ao tema da curadoria, e em grande parte seu tópico é a História das Exposições. ${ }^{7}$ Além disso, apareceu uma infinidade de antologias (principalmente com títulos bastante genéricos, como "What Makes a Great Exhibition?", "Curating Subjects" ou "Everything You Always Wanted to Know about Curating But Were Afraid to Ask") que também são dedicadas ao campo curatorial; assim como palestras, conferências e eventos com curadores sobre (suas próprias) exposições. A seguir, tentarei delinear esse fenômeno com mais precisão e investigar que concepção da História das Exposições sustenta esse discurso.

Uma primeira característica compartilhada pelas publicações acima mencionadas é o lugar de fala a partir do qual as exposições são discutidas e as formas de discurso utilizadas para fazê-lo. São quase que exclusivamente os próprios curadores que aparecem em posições de autoria, levando a uma situação em que o/a curador/a fala sobre e pelo objeto que ele/ela produziu. Mesmo quando curadores não falam sobre suas próprias exposições, falam de um lugar que não é de alguém supostamente isento e externo. Essa é uma das razões pelas quais a entrevista - que geralmente é entendida, ou pelo menos quer ser lida, como uma forma de história oral - é um formato tão popular. ${ }^{8}$ No livro de

\footnotetext{
5- Anne d'Harnoncourt, Werner Hofman, Jean Leering, Franz Meyer, Seth Siegelaub, Walter Zanini, Johannes Cladders, Lucy Lippard, Walter Hopps, Pontus Hultén e Harald Szeemann. 6 - Isso não é bem preciso no entanto; exemplos anteriores incluem "Manifesta Journal" (desde 2003) "Displayer" (2006-2012) ou "On Curating" (desde 2008). Outras revistas curatoriais fundadas após "The Exhibitionist" incluem: "Journal of Curatorial Studies", "Red-Hook" e "Well-Connected" (todos desde 2012). 7- "The Exhibitionist" aparece em uma edição de 3000 - em comparação, "October" tem uma circulação total de 1650 - , mas dificilmente é encontrado em catálogos de bibliotecas e raramente é citado. Em primeiro lugar, isso pode estar relacionado à curta existência da revista, no entanto, "The Exhibitionist" também não se destina à recepção nos círculos acadêmicos. O objetivo, como afirma o primeiro editorial, é criar um periódico "por curadores e para curadores" (ver HOFFMANN, Jens. "Overture”. In: The Exhibitionist, n 1,2010 , pp. 3-4), o que sugere uma separação entre a disciplina Curadoria e a disciplina História da Arte.

8- 0 problema da história oral e as várias implicações do formato da entrevista não poderão ser tratados nos limites deste texto. Ver: IMHOF, Dora; OMLIN, Sybille (eds.). Interviews. Oral History in Kunstwissenschaft und Kunst. München: Verlag Silke Schreiber, 2010; e DIERS, Michael; BLUNCK, Lars; OBRIST, Hans-UIrich (eds.). Das Interview. Formen und Foren des Künstlergesprächs. Hamburg: Philo Fine Arts, 2013
} 


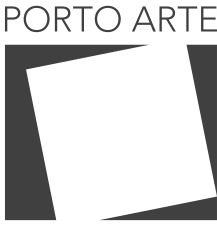

Revista de Artes Visuais

$\vee 25 n .43$

Jan/jun 2020 e-ISSN: 2179-8001

Obrist, bem como em outras antologias de entrevistas ${ }^{9}$, o/a curador/a se torna o principal protagonista de um discurso sobre a exposição e, dentro de sua historiografia, ele/ ela é igualmente sujeito e objeto. "A Brief History of Curating" é menos sobre a História da Curadoria sugerida no título, do que uma história por e sobre curadores contada na perspectiva da primeira pessoa. A forma da entrevista, como uma forma de discurso aparentemente sem mediação, reforça a suposta autenticidade das declarações e constrói uma forma de autoridade que, por sua vez, legitima o curador como autor da exposição. Tais gestos de autenticidade são menos sobre a verdade documental de quem fala e mais sobre um tipo de justificativa, uma ênfase na autoridade, a fim de legitimar atos de fala (WETZEL, 2003). 0 tom de tais entrevistas é casual, harmonioso e estritamente afirmativo. As pessoas se conhecem, citam umas às outras, e as críticas são vistas como inadequadas. As entrevistas assumem implicitamente que o/a curador/a é ele/ela próprio/a o/a melhor intérprete de seu trabalho. Após o comentário de Isabelle Graw sobre entrevistas com artistas, podemos descrever isso como "fé na intenção" (GRAW, 2013, p. 298). Para exagerar um pouco, significa que as próprias declarações dos curadores já são consideradas uma história ${ }^{10}$. Portanto, é menos a afirmação propriamente dita que é problemática do que a maneira como é formulada (GELSHORN, 2003) ${ }^{11}$.

Algo similar é encontrado na revista "The Exhibitionist". ${ }^{12}$ Seu editor Jens Hoffmann, o conselho editorial ${ }^{13}$ e os autores são recrutados no "quem é quem" da cena internacional da curadoria, e é por isto que a revista pode ser exemplar para o discurso curatorial. Ela não contém entrevistas, mas na seção "Rear Mirror" os curadores escrevem sobre suas próprias exposições, muitas vezes bastante recentes; enquanto outra seção apropriadamente intitulada "Curator's Favorites" é dedicada à análise de exposições históricas, mais uma vez pelos curadores. Se os textos sobre as exposições dos próprios curadores podem, nos melhores casos, expandir os contextos de um programa, esclarecer possíveis incompreensões e descrever a exposição no contexto de sua recepção; não devemos esquecer que o lugar de fala está ligado a intenções concretas. As declarações feitas podem oscilar entre castigos autocríticos e elogios descarados, mas revelam mais sobre o/a autor/a do que sobre a história da exposição. A seção "Curator's Favorites" também não consegue realizar qualquer análise aprofundada e, certamente, esta não é sua intenção. Aqui também descobrimos mais sobre o autor e

\footnotetext{
9- Por exemplo: THEA, Carolee (ed.). Foci: Interviews with Ten International Curators. New York: Apex Art: 2001; Id., ib. (ed.). On Curating: Interview with Ten International Curators. New York: D.A.P., 2009. Outro exemplo: OBRIST, Hans-Ulrich. Everything You Always Wanted to Know About Curating But Were Afraid to Ask. Berlin: Sternberg Press, 2011. Obrist já foi ele mesmo entrevistado sobre "sua" história por mais de uma dúzia de curadores, autores, artistas e arquitetos.

10- Uma análise mais aprofundada, que não podemos tentar aqui, deve comparar declarações de curadores, o tipo de perguntas e a construção de posições de sujeitos com entrevistas ou biografias de artistas - seria possível encontrar paralelos óbvios e até empréstimos entre as duas formas de autoapresentação. 11- O ensaio de Julia Gelshorn examina essa questão com relação às entrevistas com artistas e seu uso na História da Arte.

12- Quero enfatizar que "The Exhibitionist" não é um periódico de arte, e que eu não consideraria primeiramente meras resenhas e críticas sobre exposições como parte da História das Exposições. "The Exhibitionist" nunca emite julgamentos críticos nesse sentido; ainda que nas exposições ali discutidas existam fundamentos relevantes para a prática curatorial.

13- Christov-Bakargiev, Okwui Enwezor, Kate Fowle, Mary Jane Jacob, Constance Lewallen, Maria Lind Chus Martínez, Jessica Morgan, Julian Myers, Hans-Ulrich Obrist, Paul O'Neill, Adriano Pedrosa, Dieter Roelstraete e Dorothea von Hantelmann
} 


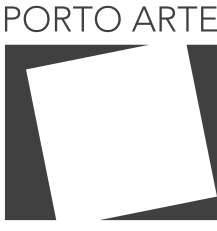

Revista de Artes Visuais

$\vee 25 n .43$

Jan/jun 2020 e-ISSN: 2179-8001

seu investimento em uma história particular do que sobre o objeto investigado. 0 fato de que os curadores sejam tanto autores quanto objetos de sua próprias análises é igualmente sintoma e causa do discurso curatorial.

$\mathrm{Na}$ relação entre o lugar de fala e as formas de discurso, também podemos determinar o objeto da História das Exposições no discurso curatorial. Centra-se principalmente no/a próprio/a curador/a e não na exposição em si, embora esta seja determinada por múltiplos atores humanos e não humanos; de acordo com a teoria ator-rede, podemos considerar não apenas o trabalho exibido, mas também, para citar apenas alguns aleatoriamente de uma lista infinitamente extensa: assistentes, estagiários não remunerados, montadores. Podemos continuar essa linha de argumentação refletindo sobre o conceito de trabalho - algo que não é mencionado em "The Exhibitionist", nem nas monografias e antologias mencionadas acima, embora tenha sido objeto de investigação em outras áreas do discurso curatorial. 0 que é necessário, então, é um exame que situaria a atividade do curador dentro de uma discussão sobre trabaIho imaterial ${ }^{14}$ ou, respectivamente, como parte de uma "política baseada em projetos" (BOLTANSKI, CHIAPELLO, pp. 147-210; MARCHART, 2012, pp. 29-41) e que, portanto, necessariamente incluiria a produção de um discurso autorreflexivo. Isso não deve, de forma alguma, excluir a parte criativa, artística ou autoral do trabalho curatorial, mas deve situá-lo dentro de uma crítica da economia política da indústria cultural.

A função de autoria do/a curador/a e sua possível relação com conceitos anacrônicos de gênio é uma questão que não poderei aprofundar no enfoque e limites deste texto (VOGEL, 2014). 0 mesmo para a comparação da posição do artista com a do curador (VIDOKLE, 2010) ${ }^{15}$. O que importa aqui é estabelecer a centralidade da figura do curador para esse discurso da história da sua exposição.

0 intenso interesse pelo lugar central do curador na exposição é ainda mais reiterado pelo estabelecimento de conceitos e pseudo-teorias como "the curatorial" - uma frase que em alguns lugares substitui "the exhibition". As implicações do verbo bastante jovem "to curate" são reveladoras, uma vez que se refere a uma atividade de curadoria que contrasta com a relação anteriormente distanciada com o processo artístico. Maria Lind (2010, p. 64) define o conceito de "curatorial", que ela desenvolve segundo a diferenciação de Chantal Mouffe entre "politics" e "the political", como "uma presença mais viral que consiste em processos de significação e relações entre objetos, pessoas, lugares, idéias e assim por diante, uma presença que se esforça para criar ficção e promover novas ideias". Comparado ao "curatorial", o "curating" para Lind é apenas o aspecto técnico, a mera organização e administração de uma exposição. Embora Lind fale constantemente em trocas e relações como a essência do "curatorial", existe uma ordem hierárquica em vigor, dominada pelo curador e reforçada pela escolha do vocabulário de Lind.

\footnotetext{
14- O início de tal abordagem é encontrado em Magda Tyzlik-Carver, "Interfacing the Commons: Curatoria System as a Form of Production on the Edge", <https://tm-resource.projects.cavi.au.dk/1037/>, acesso em 31.05.2020; oncurating.org No. 16, 2013, <http://oncurating-journal.de/index.php/issue-16.html\# UmUYSJQ2y3w>, acesso em 31.05.2020, bem como o projeto de pesquisa e evento Projekt Europa (Kunstverein München 2004). Muito obrigado a Sabeth Buchmann pela referência a Tyzlik-Carver. 15- Veja também "Letters to the Editors: Eleven Responses to Anton Vidokle's 'Art Without Artists?'”. In: e-flux Journal, No. 18, September 2010, <https://www.e-flux.com/journal/18/67472/letters-to-the-editors-eleven-responses-to-anton-vidokle-s-art-without-artists/>. Acesso em 30.05.2020.
} 


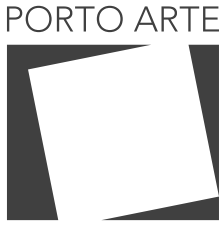

Revista de Artes Visuais

v. 25 ก. 43

Jan/jun 2020 e-ISSN: 2179-8001

Além desse foco na figura do curador, há uma notável tendência de apresentar as exposições como singularidades. É claro que esse problema também ocorre na História das Exposições acadêmica, e isso não significa que não haja análise do contexto local, político ou social das exposições. Por "singularidade", quero dizer que há muito pouca análise de exposições em conexão com outras exposições, embora tal comparação sincrônica faça sentido por várias razões. Poderíamos analisar não apenas exposições semelhantes, como "When Attitudes Become Form" e "Op Losse Schroeven" no excelente estudo de Christian Rattemeyer intitulado "Exhibiting the New Art" (RATTEMEYER, 2010); mas também incluir outras exposições que ocorreram ao mesmo tempo, como "Tucuman Arde", em Buenos Aires, e "Lucy Lippards Numbers", criando assim uma compreensão da ambivalência da arte conceitual. Ou podemos incluir a exposição "Konzeption - Conception", de Konrad Fischer, em Leverkusen, que incluiu muitos dos mesmos artistas que as exposições em Berna e Amsterdã, com resultados muito diferentes, e que também é relevante para o surgimento do mercado de arte.

Podemos ainda observar uma crescente "fobia por obras de arte", para usar a expressão bastante autocrítica de Julian Myers (2011, p. 27), no discurso da História das Exposições. Essa fobia, por sua vez, implica um conceito particular de obra de arte desenvolvida em e através de exposições, o que, no entanto, raramente é entendido e enquadrado como tal. ${ }^{16}$

Há também uma falta de descrição e análise da noção curatorial de produção e, geralmente, nenhuma tipologia de formatos expositivos. Provavelmente a tarefa mais difícil que as exposições nos apresentam é como abordar sua efemeridade. Mesmo que tenhamos documentação fotográfica, em vídeo e plantas, que nos permitem saber em parte quais obras de arte foram expostas, em que relação umas com as outras e como foram exibidas; isso só pode fornecer o pano de fundo para uma necessária análise e interpretação aprofundadas - para a qual nos faltam terminologias e conceitos definitivos.

Em vez de abordar essas deficiências e procurar maneiras de superá-las, o que implicaria empreender uma teorização ${ }^{17}$ do objeto "exposição", os autores do discurso curatorial recuam para banalidades, descrição positivista de obras de arte e uso de conceitos curatoriais para orientar a leitura das exposições. Como resultado, o desenvolvimento real e a manifestação concreta de uma exposição aparecem como

\footnotetext{
16- 0 fato de que as exposições sejam compostas de objetos materiais (em exposições de arte, geralmente obras de arte) soa mais óbvio do que parece na História das Exposições. Podemos fazer perguntas, por exemplo, sobre os efeitos de um conceito expositivo na obra de arte, sobre as relações com outras obras e as respectivas mudanças na recepção e interpretação. Peter Osborne (2013, p. 162) comenta que "tais obras são intrinsecamente duplamente-codificadas: têm seus próprios [...] significados e modos de experiência e têm sentidos mais 'pós-autônomos' que se acumulam como resultado de seu lugar geral [...] na lógica da construção da exposição. Essa é uma lógica que é contraditória em si mesma: dividida entre a apresentação do valor de exibição coletivo das obras e seus valores de uso putativos como modelos dentro de um programa especulativo de construção social. Tais programas são amálgamas incômodas de arte economia e política".

17- "As teorias tornam-se funções da ciência, porque as ciências resolvem o problema da inadequação do mundo com a ajuda da teoria - em termos positivos e concretos, porque as ciências delegam a tarefa de proteger seus objetos em teorias que colocam as questões centrais [...] O efeito surpreendente é que tais teorias pretendem encontrar o objeto, enquanto na verdade o constituem como um objeto. Em termos concisos: as teorias entregam os objetos da ciência!" (JAHRAUS, 2011, p. 29). Tentativas de uma "teoria da exposição" são encontradas, por exemplo em: SCHWARTE, 2010.
} 


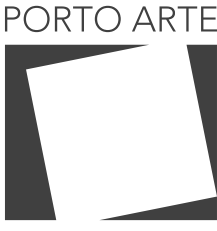

Revista de Artes Visuais

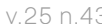

Jan/jun 2020 e-ISSN: 2179-8001

um imperativo natural e imutável. Aqui, chama atenção que não haja engajamento com os esforços correspondentes nos campos da História da Arte e dos Estudos Museológicos, além da Crítica Institucional, que desenvolveram abordagens mais críticas para museus e instituições similares. É claro que as exposições não são de forma alguma idênticas aos museus, no entanto essa diferenciação pode ser o trabalho de um corpo teórico emergente.

A questão do objeto da História das Exposições também inclui a de seu cânone, que abordarei apenas brevemente aqui. 0 cânone expositivo do discurso curatorial é diferente do da História da Arte acadêmica, o que significa que também neste caso devemos falar de uma pluralidade de cânones. Também para as exposições, os critérios para a integração ao cânone são que elas, por um lado, devam se destacar em relação a outras exposições de seu tempo e local específicos e, ao mesmo tempo, alcançar um significado universal (SHEIKH, 2010/2012, p. 14). Um problema do discurso curatorial é que ele se concentra quase que exclusivamente em exposições a partir da década de 1960 em diante. Essa limitação mostra, por um lado, que o conceito de exposição no discurso curatorial está vinculado ao curador, enquanto se distancia das exposições em contextos tradicionais de museus ou baseadas em coleções. Por outro lado, aponta para uma negação da historicidade das exposições. Embora tenham havido inovações radicais no campo da produção de exposições desde os anos 1960 - tanto pelo surgimento de curadores quanto pelos novos desafios postos pela obra de arte ("desmaterializada") -, essas inovações são reconhecidas apenas como tal quando situadas e delimitadas por uma tradição maior, que começa ao tardar do século XVIII. Por isso, apontaria uma necessária reivindicação por uma longue durée da História das Exposições, comprometida em trabalhar com suas várias continuidades e rupturas. Em contrapartida, a questão sobre quem é admitido no cânone e se se deve estabelecer um contra-cânone me parece pouco interessante. É muito mais importante analisar quem tem o direito de escrever o cânone, de que posição isso acontece e quais objetos ou práticas o cânone está tentando legitimar (ZIAJA, 2013, p. 31).

Isso se refere ao nosso próximo ponto, sobre a função estratégica da História das Exposições no discurso curatorial. Não surpreendentemente, eu argumentaria que essa função pode ser descrita como um tipo de legitimação ou autolegitimação, que definitivamente parece implicar um modelo genealógico. Apropriadamente, o posfácio de Daniel Birnbaum para "A Brief History of Curating", de Obrist, descreve os curadores reunidos no livro como "pais" e "avós" de Obrist (BIRNBAUM, 2008, p. 293). $O$ discurso curatorial da história da exposição constrói, assim, uma tradição que determina a prática de seus autores; enquanto essa prática, por sua vez, determina precedentes históricos e os objetos que constituem uma História das Exposições. A História das Exposições aqui significa, em um primeiro passo, o estabelecimento de uma suposta tradição, apenas para se inscrever, em um segundo passo, dentro dessa tradição. Simultaneamente, são estabelecidos compromissos que implicam um tipo de padronização para os estudantes de estudos curatoriais e, embora não necessariamente levem à imitação, acabam por estabelecer como um pré-requisito o compromisso com certas idéias, exposições e práticas (SHEIKH, 2010/2012, p. 15). 


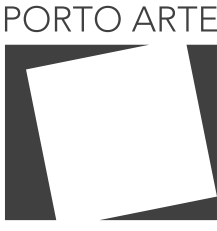

Revista de Artes Visuais

$\vee 25 n .43$

Jan/jun 2020 e-ISSN: 2179-8001

Devemos assim sempre perguntar: quem fala e de que posição estratégica de poder esses atos de fala são executados? Além disso, devemos refletir sobre o que secretamente sugerem, incluindo as coisas que não foram ditas.

Como conclusão, gostaria de incluir algumas reflexões sobre a padronização e homogeneização dos formatos expositivos. 0 discurso curatorial da História das Exposições como esboçado acima concebe seu objeto, a exposição, explicitamente como global, transnacional e transcultural, reivindicando assim um modelo universalista da exposição. Embora se reconheça que as exposições possam conter e operar com julgamentos de valor e contribuir para o estabelecimento de hierarquias - a exposição "'Primitivism' in 20th Century Art: Affinity of the Tribal and the Modern", do MoMA, em 1984, é um exemplo proeminente disso -, a própria exposição é vista como uma forma neutra.

O formato bienal ${ }^{18}$ e outras exposições de larga escala são considerados a manifestação paradigmática desse modelo e do curador transnacional como ator principal. Quando as convenções são construídas por uma História das Exposições que se considera transcultural, essas convenções, por sua vez, definem e têm um efeito normativo sobre essa forma supostamente global de produção de exposições. Esse ciclo de feedback ocorre diretamente, uma vez que os autores do discurso curatorial são importantes pelo poder de decisão - e de sua exibição.

A reivindicação ao universalismo de exposições globais e transnacionais é problemática pelo menos de dois modos. Em primeiro lugar, a reivindicação implícita dificilmente é realizada, mesmo em um nível superficial. Obrist, por exemplo, entrevista exclusivamente curadores brancos e ocidentais, dos quais apenas duas são mulheres; e das exposições discutidas em "The Exhibitionist", quase todas ocorreram nos Estados Unidos e na Europa. Por outro lado, a noção de discurso transnacional implica não apenas que exposições em, digamos, Dakar ou Berlim sejam comparáveis, mas supõe sua total comensurabilidade. Assim como na ideia neoliberal de globalização, as desigualdades e os domínios hegemônicos são simplesmente desconsiderados. Como podemos lidar com esse problema?

Eu iria além dos críticos de exposições como "Magiciens de la Terre", que reconhecem a intenção positiva de realizar uma exposição com um conceito global de arte contemporânea, mas a interpretam como um fracasso porque, como Christian Kravagna expressa, a exposição "apenas mudou do primitivismo modernista para o neo-exotismo da pós-modernidade" (KRAVAGNA, 2013, p. 52).

Uma afirmação como essa requer uma teorização aprofundada da exposição, que vai além de examinar a construção da alteridade ou igualdade através da exposição; para o investimento em uma análise de como a exposição como tal é uma forma hegemônica.

Diante das demandas contemporâneas por uma História da Arte global, devemos

18- O termo "bienal" está aqui menos associado à Bienal de Veneza e ao sistema de pavilhões nacionais do que a exposições periódicas em larga escala em geral. As bienais de hoje são menos orientadas em torno do modelo de Veneza; sua genealogia é mais precisamente marcada a partir da primeira edição da Documenta (Kassel, em 1955) ou à primeira Documenta com um diretor artístico (1972), bem como à crescente globalização deste formato após, por exemplo, a segunda e terceira Bienal de Havana $(1984,1989)$. 


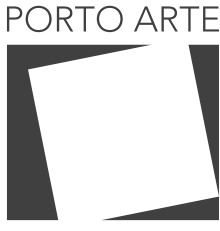

Revista de Artes Visuais

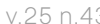

Jan/jun 2020 e-ISSN: 2179-8001

questionar não apenas as bases ideológicas - isto é, políticas, econômicas e culturais (essencialmente coloniais) - nas quais repousa a ideia de "global" (OKEKE-AGULU, 2007, pp. 202-207), mas também produzir uma crítica ideológica da forma da exposição e do discurso da História das Exposições.

\section{REFERÊNCIAS}

ALTSHULER, Bruce. "A Canon of Exhibitions". In: Manifesta Journal, No. 11, 2010/2012. AUBART, François; DERIEUX, Florence (eds.). Harald Szeemann: Individual Methology. Zurich: JRP Ringier, 2007.

BEZZOLA, Tobia; KURZMEYER, Roman. Harald Szeemann: With by through because towards despite - Catalogue of All Exhibitions 1957-2005. Zurich: Voldemeer, 2007.

BIRNBAUM, Daniel. "The Archeology of Things to Come". In: OBRIST, Hans-Ulrich. A Brief History of Curating. Zürich: JRP Ringier, 2008, p. 293-298.

BOLTANSKI, Luc; CHIAPELLO, Ève. The New Spirit of Capitalism. London: Verso, 2007.

BOURRIAUD, Nicolas. Relational Aesthetics. Paris: Les presses du réel, Dijon, 2002.

GELSHORN, Julia. "Der Produzent als Autor. Künstlerische Theorie als kunsthistorische Herausforderung". In: KRIEGER, Verena (ed.). Kunstgeschichte und Gegenwartskunst. Vom Nutzen und Nachteil der Zeitgenossenschaft. Cologne: Böhlau, 2008, pp. 193-211.

GRAW; Isabelle. "Reden bis zum Umfallen. Das Kunstgespräch im Zeichen des Kommunikationsimperativs". In: DIERS, Michael; BLUNCK, Lars; OBRIST, Hans-Ulrich (eds.). Das Interview. Formen und Foren des Künstlergesprächs. Hamburg: Philo Fine Arts, 2013, p. 298.

JAHRAUS, Oliver. "Theorie theorie". In: GRIZELJ, Mario; JAHRAUS, Oliver (eds.). Theorietheorie. Wider die Theoriemüdigkeit in den Geisteswissenschaften. Munique: Fink, 2011, pp. 17-39.

LIND, Maria. "The Curatorial". In: WOOD, Brian Kuon (ed.). Selected Maria Lind Writing. Berlin: Sternberg Press, 2010.

KRAVAGNA, Christian. "Postkoloniale Ausstellungen im Kunstfeld". In: ARGE schnittpunkt (ed.). Handbuch Ausstellungstheorie und-praxis. Cologne et al., 2013, p. 51-65).

MARCHART, Oliver. "The Curatorial Subject. The figure of the curator between individuality and collectivity". In: Texte zur Kunst, No. 86, (22) 2012, pp. 29-41.

MYERS, Julian. "On the Value of a History of Exhibitions". In: The Exhibitionist, No. 4, 2011.

MÜLLER, Hans-Joachim. Harald Szeemann: Ausstellungsmacher. Ostfildern-Ruit: Hatje Cantz, 2006.

OBRIST, Hans Ulrich. A Brief History of Curating. Zurich: JRP Ringier, 2011.

OKEKE-AGULU, Chika. "Art History and Globalization". In: ELKINS, James (ed.). Is Art History Global?. New York and London: Routledge, 2007, pp. 202-207.

OSBORNE, Peter. Anywhere. Or Not At All. Philosophy of Contemporary Art. London: Verso, 2013.

RATTEMEYER, Christian. Exhibiting the New Art: 'Op Losse Schroeven' and 'When Atti- 


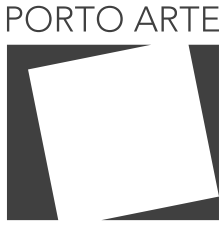

Revista de Artes Visuais

v. 25 ก. 43 tudes Become Form' 1969. Cologne: König, 2010.

SHEIKH, Simon. "On the Standard of Standards, or, Curating and Canonization". In: Manifesta Journal, No. 11, 2010/2012.

SCHWARTE, Ludger. "Politik des Ausstellens". In: BERG, Karen van den; GUMBRECHT, Hans Ulrich (eds.). Politik des Zeigens. Munique: 2010, pp. 129-141.

VOGEL, Felix. "Autorschaft als Legitimation. Der Kurator als Autor und die Inszenierung von Autorschaft in 'The Exhibitionist'". In: KYORA, Sabine (ed.). Subjektform Autor? Autorschaftsinszenierungen als Praktiken der Subjektivierung. Bielefeld: transcript Verlag, 2014, pp. 157-176.

WETZEL, Michael. "Artefaktualitäten: Zum Verhältnis von Authentizität und Autorschaft". In: KNALLER, Susanne; MÜLLER, Harro (eds.). Authentizität. Diskussion eines ästhetischen Begriffs. Munich: Fink, 2003, pp. 37-54.

ZIAJA, Luisa. "Ausstellungsgeschichten. Ansätze der Historisierung im Kunstfeld". In: ARGE schnittpunkt (ed.). Handbuch Ausstellungstheorie und-praxis. Cologne et al., 2013, pp. 23-34. 


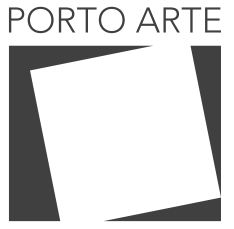

Revista de Artes Visuais

v. $25 \mathrm{n} .43$

Jan/jun 2020

e-ISSN: 2179-8001

\section{Felix Vogel}

Curador e pesquisador de história da arte, teoria da mídia e filosofia. Pós-doutorando e professor na Universidade de Basel. Seus interesses de pesquisa incluem a teoria e a história das exposições e da arte transcultural. Foi curador de exposições como a $4^{\text {a }}$ Bienal de Bucareste (2010).

Texto recebido em: 15/06/2020

Texto publicado em: 30/06/2020 